\title{
Sensitivity analysis of feedback control for Concrete Core Activation and impact on installed thermal production power
}

\author{
Maarten Sourbron \\ KU Leuven Association, Department of Engineering Technology \\ Maarten.Sourbron@mech.kuleuven.be* \\ Lieve Helsen \\ KU Leuven, Department of Mechanical Engineering
}

Lieve.Helsen@mech.kuleuven.be

March 15, 2013

\begin{abstract}
Because Concrete Core Activation (CCA) actively integrates building mass in the HVAC system, the choice of control strategy and controller settings plays a decisive role in reaching both thermal comfort and low energy use. Although not capable of intrinsically taking into account the system dynamics, conventional feedback control is often applied in CCA buildings. This paper defines the basic characteristics a CCA-controller should have, by making a sensitivity analysis of the main parameters in a conventional feedback control loop. Without prior knowledge, these parameters are varied, and the behaviour of the controller with the best performance is analysed with respect to energy and thermal comfort. It shows that a performant CCA-controller keeps the CCA core temperature at a constant level of around $1^{\circ} \mathrm{C}$ higher than the lower thermal comfort limit during the whole year. This ensures high thermal comfort and low energy use with a low installed production power.
\end{abstract}




\section{Contents}

1 Introduction 2

2 System description 5

3 Controller performance indicators 14

$\begin{array}{lll}4 & \text { Results } & 16\end{array}$

$\begin{array}{lll}5 & \text { Conclusions } & 27\end{array}$

\section{Introduction}

Concrete Core Activation (CCA, also called Thermally Activated Building Systems or TABS) is a heat and cold emission system where water tubes are embedded in the core of the concrete floor slab of a building. Heated or cooled water flows through the tubes, heats up or cools down the concrete of the floor slab, which on its turn conditions the rooms below and above.

Due to the active integration of building mass in the HVAC system, the choice of control strategy and controller settings plays a decisive role in reaching both thermal comfort and low energy use. Indeed, concrete Core Activation (CCA), with its high thermal inertia, is the connection between the heat and cold production system and the building where thermal comfort has to be guaranteed. It is crucial to take CCA dynamic thermal behaviour into account when designing the control system. However, CCA buildings are often operated with controllers using conventional feedback algorithms. Several authors [5, 7, 10, 11, 12, 17, 18, 20] reported on conventional control strategies for CCA or radiant floor systems in general.

Analysing simulation results, Olesen [10] proposed to keep the concrete core at a constant temperature of $22^{\circ} \mathrm{C}$ as a very simple control strategy for buildings with a low heating and cooling load.

Olesen et al. 111] studied the effect on the energy use of pump operation time, intermittent pump control and supply water temperature using a simulation model of a CCA office building in summer period. Night time 
operation was beneficial from the energy point of view, but with a slightly higher thermal discomfort. Intermittent pump control could dramatically lower energy use, while maintaining a comparable level of thermal comfort. For the supply temperature, a slightly inclined, outdoor temperature dependent cooling curve appeared to be the best in balancing energy use and thermal comfort.

In their building controller simulation study, G untensperger et al. [5] defined one supply temperature curve, depending on the outdoor temperature, in combination with a pump operation time control. Moreover, they added the concrete core temperature as an extra corrective variable. This concrete core temperature together with the room air temperature was used to correct the calculated supply temperature.

Tian and Love [18] investigated measurements in a real office building. A slab cooling system was circulating constant flow, high temperature chilled water. This system was combined with a Variable Air Volume (VAV) system with terminal reheat coils and with radiant heating panels. They observed conflicting behaviour between CCA and the ventilation system, for which the controller had to be corrected by applying individual time schedules for both CCA and ventilation system and by adapting heating and cooling set points.

Zaheer-uddin et al. [20] simulated and compared conventional on-off control with an adapted multi-stage on-off control and with an improved proportional controller. They demonstrated that the improved proportional control of a radiant floor heating system, which used an initial constant gain on top of the proportional gain, resulted in a robust controller, yielding a stable control of the room temperature.

Rijksen et al. 12] presented a combined measurement and simulation study of an office building in the Netherlands. They controlled the CCA cooling during the night and in the weekend starting from 3 PM. CCA cooling was operational for a room temperature above $22.5^{\circ} \mathrm{C}$ and stopped below $22.0^{\circ} \mathrm{C}$, with a supply water temperature of $15^{\circ} \mathrm{C}$. During office hours only conditioned ventilation was active. For higher cooling loads, the CCA were 
also activated during the day. The results pointed at a reduction of required cooling power of up to $50 \%$, compared to the peak heat load value. Results of the acquired thermal comfort were not mentioned.

Kolarik et al. [7] presented a simulation study of a two zone office building separated by a corridor. Comparing a VAV-system and a CCA system combined with a Constant-Air-Volume (CAV)-system, the results showed a $20 \%$ primary energy reduction for the CCA system. Thermal discomfort increased with the CCA, although an adapted control strategy limited the number of hours violating the $\mathrm{PPD}=10 \%$-limit to $2 \%$ on a yearly basis. The adapted control strategy consisted of a changed pump operation and a lower water supply temperature.

A case study of a small office building presented by Sourbron et al. [17] demonstrated that changing the controller settings for room air temperature feedback control, has a major impact on the resulting thermal comfort and energy use. Non adapted settings lead to inefficient use of energy, as observed in measurements as well as in simulation results.

These results show that an appropriate choice of controller settings, can result in well-controlled systems, without the need for optimal control strategies. However, the studies published always limit their analysis to a predefined subset of controller parameters and do not provide clear insight in which thermal behaviour aspects are leading to good controller performance.

In this paper, instead of investigating the impact of one or a limited number of controller settings on the system performance, the aim is to make a global sensitivity analysis of the main parameters in a conventional feedback controller. Without prior knowledge, these parameters are varied, and the behaviour of the controller with the best performance is analysed in order to define the basic CCA thermal behaviour that leads to a good system performance, with respect to energy use and thermal comfort. Furthermore, the statement that a CCA system leads to peak shaving and, as a consequence, to a reduction of the production system size [4], is examined.

Although a conventional on-off feedback control strategy is not able to intrin- 
sically take into account the thermal characteristics of CCA, analysing the controller performance using different coltroller parameter settings, yields valuable information on the transient behaviour of $\mathrm{CCA}$ and on the required features of a performant CCA controller.

\section{System description}

The thermal characteristics of CCA constraint the design and size of other system components (such as building, heat and cold production units, ...) within the global system. Therefore, the main CCA thermal characteristics are shortly described in subsection 2.1, after which the building model, system sizing, meteorological data and the conventional controller design are presented.

\subsection{CCA thermal characteristics}

Three main thermal characteristics of CCA influence the operation of the HVAC system, regardless of whether the system is in heating or cooling mode: firstly, CCA has a large thermal mass and therefore a large thermal time constant, secondly, CCA has a limited steady-state thermal power and finally, in transient regime, CCA extracts a large thermal power from the water flowing through the pipes. This transient thermal power can initially be more than double of the steady-state thermal power and, due to the large thermal time constant of typically $10-15 \mathrm{~h}$, this transient regime lasts for a long time.

These three main thermal characteristics are illustrated by Sourbron [16] using an analytical solution to describe the transient thermal behaviour of an uncovered CCA floor slab. The slab has a thickness of $20 \mathrm{~cm}$ and a tube with an outer diameter of $20 \mathrm{~mm}$ is integrated in the middle of the slab with a tube spacing of $15 \mathrm{~cm}$. A water flow rate of $150 \mathrm{~kg} / \mathrm{h}$ is applied. The whole slab is initially at $20^{\circ} \mathrm{C}$, when a step change of the water supply temperature to $30^{\circ} \mathrm{C}$ is applied. For simplicity, the temperatures of the zones below and above remain constant at $20^{\circ} \mathrm{C}$ during the whole period. Fig. 1 shows $\dot{q}_{\text {water-CCA }}$ (in dashed line), the specific thermal power from the water flow to the concrete slab and $\dot{q}_{C C A-z o n e}=\dot{q}_{C C A-z o n e, b e l o w}+\dot{q}_{C C A-z o n e, a b o v e}$ (in solid line), the sum of the power from the slab to the zone below and above. 


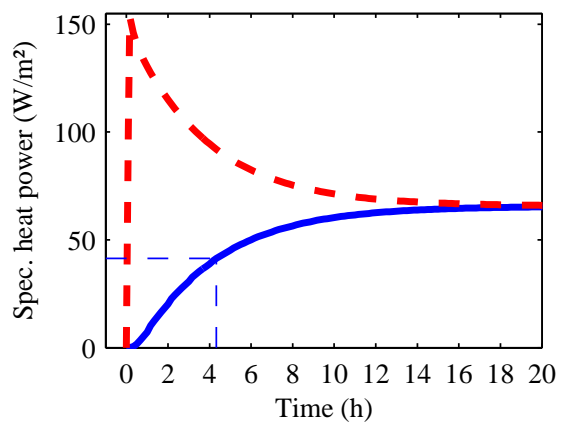

Figure 1: Specific thermal heating power $\dot{q}_{w a t e r-C C A}$ from water to concrete (- -) and $\dot{q}_{C C A-z o n e}=\dot{q}_{C C A-z o n e, b e l o w}+\dot{q}_{C C A-z o n e, a b o v e}$ from the concrete slab to the zones below and above $(-)$.

The steady-state thermal power equals $65 \mathrm{~W} / \mathrm{m}^{2}$, but initially $\dot{q}_{w a t e r-C C A}$ amounts to $153 \mathrm{~W} / \mathrm{m}^{2}$, which is a factor 2.4 higher compared to steadystate. This transient regime lasts for almost 20 hours.

These thermal characteristics imply that the CCA-control strategy, which determines when and at which temperature the water flow will be switched on, will not only influence the thermal output from CCA to the zone, but also the operation of the production system, since its thermal power is often chosen based on steady-state calculations.

Since the aim of this paper is to investigate the performance of CCA feedback control strategies, the CCA must have sufficient control authority in the whole system of production-CCA-building zone. This imposes design limitations for the building and for the production system. For the building, the CCA thermal characteristics imply that the occuring heat gains and losses in the building zone should be limited to a maximum that corresponds to the steady-state thermal power of the CCA. For cooling mode, Lehmann et al. [8] present permissible total heat gain values of $27-45 \mathrm{~W} / \mathrm{m}^{2}$ as a function of the allowed daily temperature drift. For tehproduction system, these thermal characteristics imply that the production system should be designed with sufficient thermal power to cope with the transient effects. Otherwise, expected set point temperatures will not be met due to insufficient thermal power. A simulation model of a 2-zone office building with a high quality envelope and a production system with unlimited thermal 


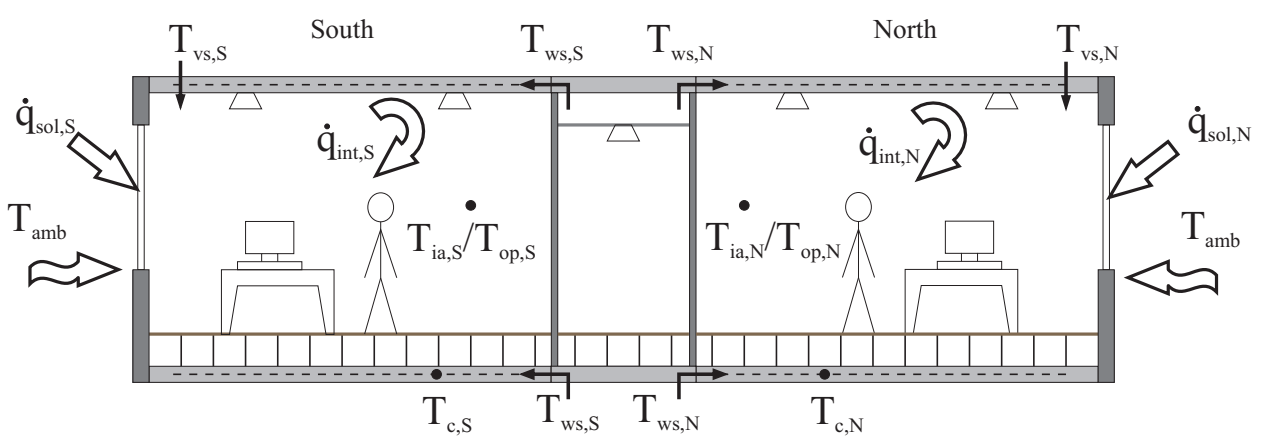

Figure 2: Schematic representation of the 2-zone office building with the disturbances ambient temperature $T_{a m b}$, solar radiation $\dot{q}_{s o l}$ and internal gains $\dot{q}_{\text {int }}$, the inputs water supply temperature $T_{w s}$ and ventilation temperature $T_{v s}$ and the measured outputs zone temperature $T_{i a}$ (or operative temperature $T_{o p}$ ) and concrete core temperature $T_{c}$.

power forms therefore the starting point of this work.

\section{$2.2 \quad 2$-Zone office building model}

A TRNSYS [15] model of a 2-zone office building is used to evaluate the controller performance, which is assessed in terms of both thermal comfort and energy use indicators.

The building considered in this study is a 2-zone office building with CCA floor and ceiling and a constant air volume (CAV) ventilation system. A schematic view is given in Fig. 2.

The 2-zone office building is supposed to be representative for a modern, high quality office building (raised floor, lighting level, ...) and is adapted to CCA (good insulation, solar shading, ... ).

The 2-zone building section is a cut-out of a typical office building with South and North oriented offices, both separated from the corridor by a light gypsum wall. The offices have a raised floor in order to provide the necessary flexibility to the work environment [13]. This is an important design condition for CCA - or by extension for any HVAC system which uses the thermal mass of the building [14] — since the heat transfer from CCA to the room is hampered. Lehmann et al. [8] concluded that using a 
raised floor compared to carpet, decreases the permissible total heat gains with $15-20 \%$ to $27-45 \mathrm{~W} / \mathrm{m}^{2}$ depending on the allowed temperature drift in the room.

Only in the corridor a suspended ceiling is placed, which is used to put the horizontal distribution of hot and cold water supply, air ducts, electricity and ICT.

The outer wall has $10 \mathrm{~cm}$ mineral wool insulation and high quality window:1. This is a high level of insulation compared to standard building practice in Belgium [9]. The combination of solar shading, having a g-value of $25 \%$, and the window, with a g-value of $36 \%$, has an the overall g-value of $0.36 \times 0.25=0.09$. The solar shading has a controller with hysteresis which lowers the shading device when $\dot{q}_{\text {sol }}>250 \mathrm{~W} / \mathrm{m}^{2}$ on the vertical South surface. It is raised again at a value of $\dot{q}_{s o l}<150 \mathrm{~W} / \mathrm{m}^{2}$. The North zone has no solar shading.

There are no walls to the adjacent building modules, which implies a landscape office is assumed. The only difference with a building having internal walls would be their thermal capacity, since the adjacent zone is assumed to be at the same temperature as the zone investigated.

Steady-state calculations of a $20 \mathrm{~cm}$ CCA-slab with raised floor, using $40^{\circ} \mathrm{C}$ heating water temperatures and $17^{\circ} \mathrm{C}$ cooling water temperatures (typical heat pump and ground cooling values), yield a steady-state thermal output of $90 \mathrm{~W} / \mathrm{m}^{2}$ for heating and $40 \mathrm{~W} / \mathrm{m}^{2}$ for cooling [16].

Table 1 summarizes the typical building parameters. For more information and other parameters of this 2-zone office building model, a detailed overview and background of these data are presented by Sourbron [16]. Table 2 summarizes the most important parameters and the different operating hours are presented in Table 3 .

\footnotetext{
${ }^{1}$ The overall window properties are the U- and g-value calculated by TRNSYS, based on the glass and frame properties. This overall U-value corresponds to the value provided by the Belgian U-value standard [1]
} 
Table 1: Building characteristics

\begin{tabular}{llc}
\hline 2 zone building parameters & & \\
\hline Floor area of the South or North zone & $\left(\mathrm{m}^{2}\right)$ & 12 \\
Floor area of the corridor & $\left(\mathrm{m}^{2}\right)$ & 4.32 \\
Total heated volume & $\left(\mathrm{m}^{3}\right)$ & 96.3 \\
Total heated area & $\left(\mathrm{m}^{2}\right)$ & 28.3 \\
Transmission area of 1 zone & $\left(\mathrm{m}^{2}\right)$ & 8.6 \\
U-value external wall & $\left(\mathrm{W} / \mathrm{m}^{2} \mathrm{~K}\right)$ & 0.41 \\
U-value total façade & $\left(\mathrm{W} / \mathrm{m}^{2} \mathrm{~K}\right)$ & 0.85 \\
Percentage of glazing & $(\%)$ & 50 \\
\hline
\end{tabular}

Table 2: Parameters of the 2-zone office building model

\begin{tabular}{ll}
\hline Parameter & Value \\
\hline Occupancy rate & 1 person per $10 \mathrm{~m}^{2}$ \\
Sensible heat gains from people & $7.5 \mathrm{~W} / \mathrm{m}^{2}$ \\
Latent heat gains from people & $5.5 \mathrm{~W} / \mathrm{m}^{2}$ \\
Appliances heat gains & $7.8 \mathrm{~W} / \mathrm{m}^{2}$ \\
Lighting heat gains & $7.5 \mathrm{~W} / \mathrm{m}^{2}$ \\
Infiltration rate & $0.05 \mathrm{ACH}$ during AHU-operation and \\
& $0.2 \mathrm{ACH}$ outside those hours \\
Ventilation rate & $36 \mathrm{~m}^{3} / \mathrm{h}$ pers (EN15251 [3] [Class II]) \\
\hline
\end{tabular}

Table 3: Scheduled operating hours of the typical office model

\begin{tabular}{ll}
\hline & Operating hours \\
\hline office hours & $8 \mathrm{AM}-6 \mathrm{PM}$ \\
people's attendance & $8 \mathrm{AM}-12 \mathrm{PM}, 1 \mathrm{PM}-6 \mathrm{PM}$ \\
Appliances & $8 \mathrm{AM}-12 \mathrm{PM}, 1 \mathrm{PM}-6 \mathrm{PM}$ \\
Lights & $8 \mathrm{AM}-6 \mathrm{PM}$ \\
Ventilation & $7 \mathrm{AM}-7 \mathrm{PM}$ \\
\hline
\end{tabular}


Table 4: Heating load (EN12831) and cooling load (VDI2078)

\begin{tabular}{lll}
\hline Heating power & $\left(\mathrm{W} / \mathrm{m}^{2}\right)$ & 26 \\
Cooling power South zone (8h-18h average) & $\left(\mathrm{W} / \mathrm{m}^{2}\right)$ & 25 \\
\hline
\end{tabular}

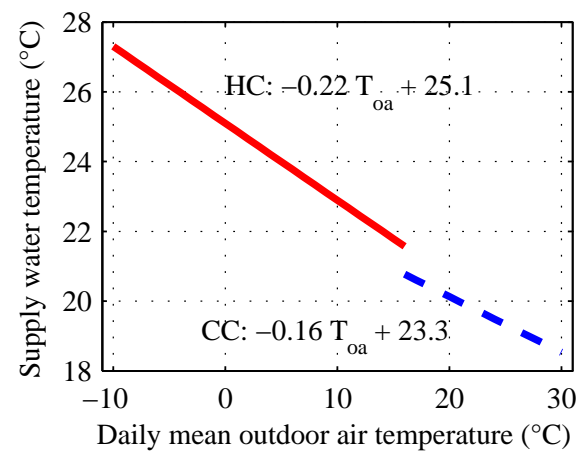

Figure 3: Heating (HC) and cooling (CC) curves for the office zone

\subsection{System sizing}

The steady-state heating and cooling load calculations of the office zones are used as a starting point for the design of the system. The heating load is calculated according to EN12831 [2] and the cooling load according to VDI2078 [19]. For the cooling power, it is assumed that peaks in the building zone are flattened out by the CCA, so the system is designed based on the average 8 AM - 6 PM load rather than on the peak load, which is $31 \mathrm{~W} / \mathrm{m}^{2}$ for the South zone and $30 \mathrm{~W} / \mathrm{m}^{2}$ for the North zone. Therefore, the design strategy of the cooling production system incorporates the assumption that peak shaving thanks to CCA occurs. The results of these calculations are summarized in Table 4, and show that the building complies with the CCA limitations on available thermal power $\left(90 \mathrm{~W} / \mathrm{m}^{2}\right.$ for heating and $60 \mathrm{~W} / \mathrm{m}^{2}$. Moreover, the thermal load from the building is lower than these values which ensures control authority of the CCA.

From these heatind and cooling loads, the heating and cooling curves of the CCA are determined and relate the ambient temperature to the supply water temperature as basic controller setting (Fig. 3 ). The steady-state thermal characteristics of the CCA-slab with raised floor are used to determine this relation. 
Table 5: Production efficiency $\left(T_{w s}\right.$ in $\left.{ }^{\circ} \mathrm{C}\right)$

\begin{tabular}{ll}
\hline & Production efficiency \\
\hline Condensing gas boiler & $\eta=0.95$ \\
Low temperature air-cooled chiller & $\mathrm{EER}=3$ \\
Low temperature heat pump & $\mathrm{COP}=-0.03\left(T_{w s}-35\right)+3.9$ \\
High temperature air-cooled chiller & $\mathrm{EER}=0.03\left(T_{w s}-18\right)+3.5$ \\
\hline
\end{tabular}

The heat and cold distribution is designed such that the South and North zone can operate independently from each other. The heat and cold production units are highly simplified in the simulation model. Since the focus of this study does not lie on the analysis of the production system, it is more convenient to choose a heat pump and chiller for which the heat source/heat sink is independent of the system operation. Therefore, the CCA heat and cold production are modelled as an air-cooled heat pump and as a high temperature air cooled chiller respectively. The heating and cooling energy delivered to the AHU are assumed to be supplied by an additional boiler and low temperature chiller system, given the required temperature levels of the heating and cooling coil.

The production efficiencies are presented in Table 5. For the nominal power of the production units, three cases are considered. Firstly, in order not to hamper CCA operation, the nominal power is set to infinite. Secondly, the impact is investigated of limiting the production power to the design thermal power, defined by the steady-state heating and cooling load calculations. And thirdly, an intermediate case of twice the design thermal power is considered.

\subsection{Meteorological data}

The Typical Meteorological Year (TMY) for Uccle, Belgium, is used in the simulation model.

\subsection{Heating/Cooling Curve controller design}

In this section, an on-off feedback control strategy for the CCA system is presented, based on a continuously measurable temperature $T_{\text {controlled }}$, thus not dependent on pump operation (Fig. 4). The controller uses the heating 


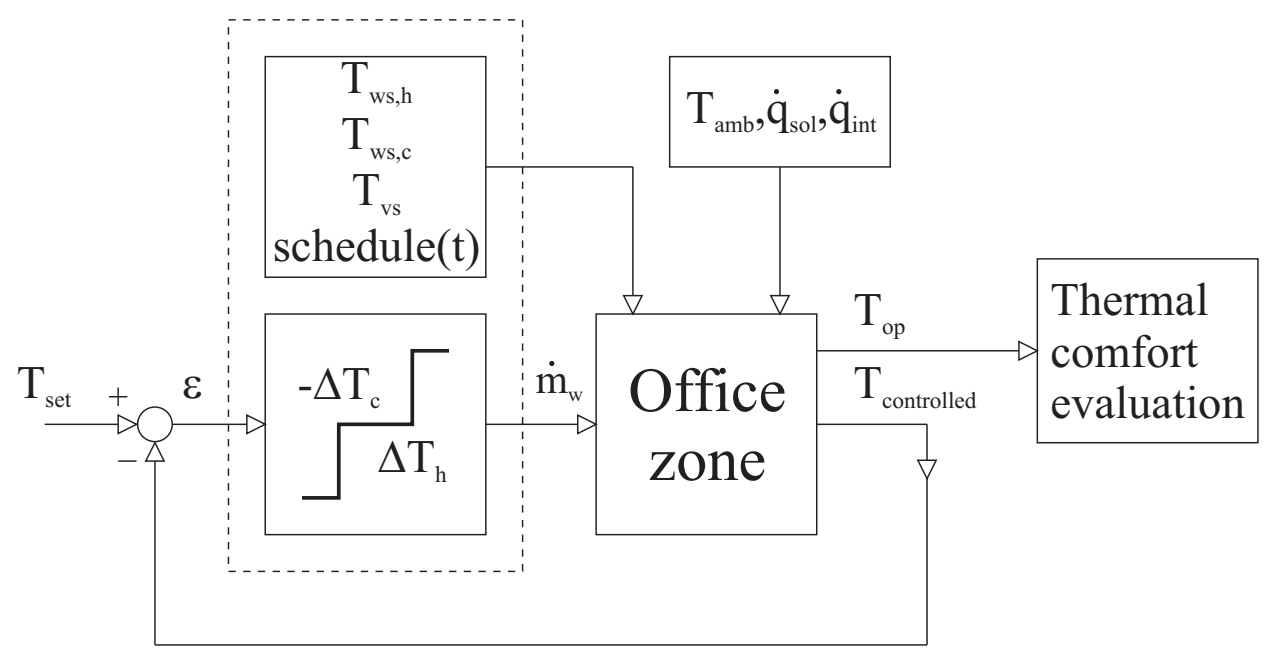

(a)

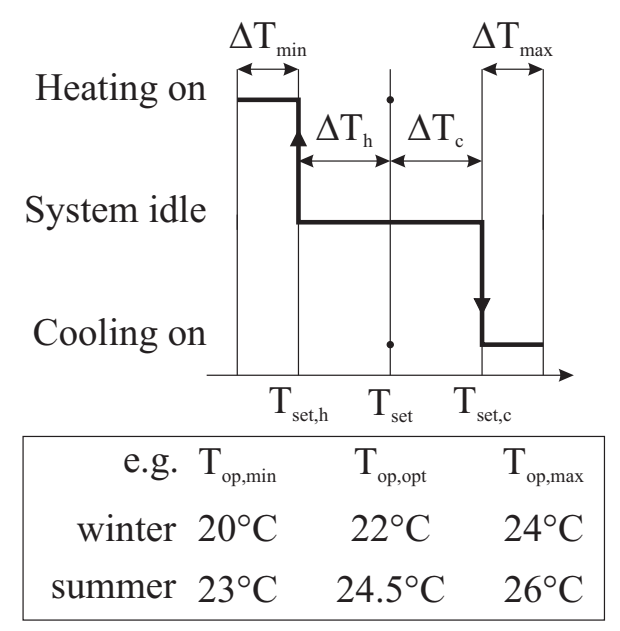

(b)

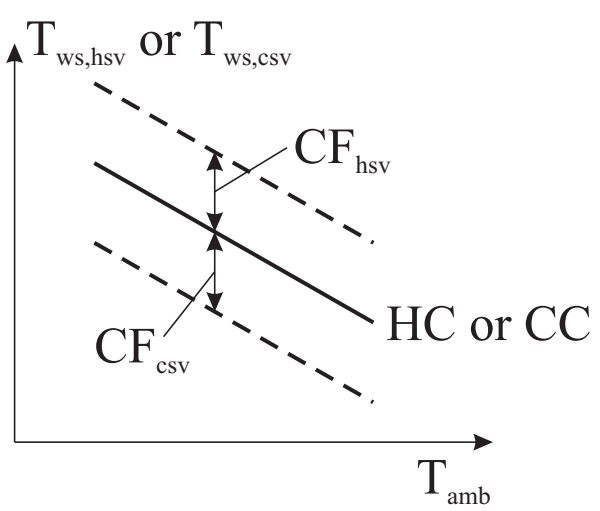

(c)

Figure 4: (a) General block diagram of the 3 stage On-Off feedback controller, (b) adaptation of the temperature set point value $\left(\Delta T_{h} / \Delta T_{c}\right)$ and (c) adaptation of the heating/cooling curve $\left(C F_{h s v} / C F_{c s v}\right)$ 
and cooling curve (HCC) from the 2-zone office building to determine the water supply temperature as a function of $T_{r m}$, the running mean outdoor temperature [3]. The following terminology is used:

- The sensor measures a temperature (= controlled variable $\left.\mathrm{T}_{\text {controlled }}\right)$ and transmits this value to the controller.

- The controller compares this value to the set point $T_{\text {set }}$ and generates a corrective action to the controlled devices. In this case a 3 stage OnOff controller is used (Fig. (4):

- Heating on if $T_{\text {controlled }}<T_{\text {set }}-\Delta T_{h}$ or $\epsilon=T_{\text {set }}-T_{\text {controlled }}>$ $\Delta T_{h}$

- No action if $T_{\text {set }}-\Delta T_{h}<T_{\text {controlled }}<T_{\text {set }}+\Delta T_{c}$ or $-\Delta T_{c}<\epsilon<$ $\Delta T_{h}$

- Cooling on if $T_{\text {controlled }}>T_{\text {set }}+\Delta T_{c}$ or $\epsilon=T_{\text {set }}-T_{\text {controlled }}<$ $-\Delta T_{c}$

- The controlled devices are the CCA ceiling and floor.

- The control agent is the heating and cooling water supplied to the CCA, of which the supply temperature $\left(T_{w s, h s v}\right.$ and $\left.T_{w s, c s v}\right)$ can vary ( $s v$ stands for setpoint value).

- The set point is the desired value of the controlled variable (temperature $\left.T_{\text {controlled }}\right)$. The band $\left(\Delta T_{h}+\Delta T_{c}\right)$ around this $T_{\text {set }}$ defines the heating and cooling setpoint: $\mathrm{T}_{\text {set,h }}$ and $\mathrm{T}_{\text {set,c }}$.

The controller parameters varied in the current simulation study are listed in Table 6. The base heating and cooling curves are derived from the results of the steady-state heating and cooling load calculations (see Fig. 3). These can be adapted by using correction factors $C F_{h s v}$ and $C F_{c s v}$, leading to the requested set point value $(s v)$ for the water supply temperature $T_{w s}$ for heating and cooling.

Since $T_{\max }$ and $T_{\min }$ vary from winter $\left(24^{\circ} \mathrm{C}-20^{\circ} \mathrm{C}\right)$ to summer $\left(26^{\circ} \mathrm{C}-23\right.$ $\left.{ }^{\circ} \mathrm{C}\right)[6,3], \Delta T_{\min }$ and $\Delta T_{\max }$ are used as controller parameter instead of 
Table 6: Overview of controller settings

\begin{tabular}{ll}
\hline & Controller settings \\
\hline Heating curve & $T_{w s, h s v}=-0.22 T_{r m}+25.1+C F_{h s v}$ \\
Cooling curve & $T_{w s, c s v}=-0.16 T_{r m}+23.3+C F_{c s v}$ \\
$C F_{h s v} / C F_{c s v}$ & $(0 / 0) ;(3 /-3) ;(6 /-6)$ \\
$T_{\text {controlled }}$ & $T_{i a}$ (indoor air); $T_{o p}$ (operative) \\
& $T_{s}$ (concrete ceiling surface) $T_{c}$ (concrete core) \\
$T_{\text {set }}$ & $T_{o p, o p t}=22^{\circ} \mathrm{C}$ (winter); $24.5^{\circ} \mathrm{C}$ (summer) \\
$T_{\max } / T_{\min }$ & $T_{o p, \max } / T_{o p, \min }$ \\
$\Delta T_{\min } / \Delta T_{\max }$ & $(0 / 0) ;(+1 /-1) ;(0 /-1) ;(0 /-2)$ \\
\hline
\end{tabular}

$\Delta T_{h}$ and $\Delta T_{c}$ :

$$
\begin{aligned}
& T_{\text {set }, h}=T_{\text {set }}-\Delta T_{h}=T_{\text {min }}+\Delta T_{\text {min }} \\
& T_{\text {set }, c}=T_{\text {set }}+\Delta T_{c}=T_{\text {max }}-\Delta T_{\text {max }}
\end{aligned}
$$

The selected controlled temperatures are all continuously measurable variables in the control system, i.e. even with a non operating circulation pump, they can provide data to the building controller. Four different controlled temperatures are evaluated: $T_{i a}$ (indoor air), $T_{o p}$ (operative), $T_{s}$ (concrete ceiling surface) and $T_{c}$ (concrete core). These controlled temperatures are chosen because they represent the temperature path from zone air to CCA water. The drawback of these controlled temperatures is the position dependency of their reading: installation of the sensors has to be carefully accomplished so that their reading gives a representative value. Other controlled temperatures like water supply or return temperature are dependent on pump operation, which is not included in this analysis. However they do not have the drawback of being position dependent.

Additional to these parameters and the corresponding settings, night setback is incorporated: $\left(T_{o p, \min }-5\right)$ and $\left(T_{o p, \max }+5\right)$ from 9 PM until 6 AM. This means that heating and cooling start up two hours before the office day starts and keeps running three hours after the end of the office day to allow pre- and post-conditioning of the building. This night setback setting will influence the peak production powers required by the system, as shown further, where cases without night setback are presented. The ventilation air temperature is controlled at $T_{o p, \min }$. The ventilation schedule is fixed: 
ON from 7 AM to $7 \mathrm{PM}$.

To clearly distinguish between the different controller settings, the following terminology is used hereafter:

- $T_{\text {controlled }}:$ CONTR $=T_{i a}, T_{o p}, T_{s}, T_{c}$

- $C F_{h s v} / C F_{c s v}: \mathrm{CF}=(0 / 0),(3 /-3),(6 /-6)$

- $\Delta T_{\min } / \Delta T_{\max }: \mathrm{SET}=(0 / 0),(1 /-1),(0 /-1),(0 /-2)$

\section{Controller performance indicators}

The controller performance is evaluated with respect to thermal comfort and energy use, together with an indication of the numer of days showing both heating and cooling. This section describes the performance indicators used.

\subsection{Thermal discomfort}

Thermal discomfort is assessed in terms of the 'Predicted Percentage of Dissatisfied' or PPD [6]. Comfort class B is used, setting the limit of the Predicted Mean Vote $\left(\mathrm{PMV}_{\text {limit }}\right)$ to 0.5 and $\mathrm{PPD}_{\text {limit }}$ to $10 \%$. The $\mathrm{PPD}$ is weighted over an observed period as described in EN15251 [3, Annex F]: every time step a weighting factor $w f=P P D_{\text {actual }} / P P D_{\text {limit }}$ is calculated if the PMV exceeds the limit of 0.5. Then, the thermal discomfort $D C$ is described as the number of PPD-hours per zone: $\mathrm{PPDh}=\sum w f \times$ timestep. Although EN15251 provides a guideline to determine how much deviation from the thermal comfort criteria can be tolerated, for simplicity, this is not used in the analysis of the results. After all, this only shifts the threshold to determine whether a building complies with the comfort class, but does not change the ranking of the different cases relative to each other.

To clarify the value of PPDh: $10 \mathrm{PPDh}$ could mean e.g. that during $5 \mathrm{~h}$ $20 \%$ of the people is dissatisfied instead of the allowed $10 \%$. A PPD of $20 \%$ corresponds to approximately $1 \mathrm{~K}$ above or below the comfort set point. 


\section{$3.2 \quad$ Energy use}

To enable a correct comparison of the different energy flows in the system, the energy use is converted to specific primary energy use $E$ (in $\mathrm{kWh} / \mathrm{m}^{2}$ ). The heat and cold supplied to the AHU's are at temperature levels imposing the use of a condensing gas boiler and low-temperature chiller. On the other hand, the CCA system requires only low exergy heat and cold, and can be fed by a reversible air-cooled heat pump, working at higher cooling water temperatures and lower heating water temperatures. Converting the end energy use to primary energy is therefore the only correct way to analyse the different heat flows. The primary energy conversion factors are $\eta_{\text {gas }}=1$ for natural gas in the gas boiler and $1 / \eta_{\text {elec }}=2.5$ for electricity in the heat pump, chiller, pumps and fans.

A distinction is made between:

- CCA conditioning $E_{C C A}=E_{C C A, h}+E_{C C A, c}+E_{C C A, p}$

- Air conditioning $E_{A H U}=E_{A H U, h}+E_{A H U, c}+E_{A H U f}$

where water through the CCA is heated by a heat pump $\left(E_{C C A, h}\right)$, cooled by a low temperature chiller $\left(E_{C C A, c}\right)$ and transported using a circulation pump $\left(E_{C C A, p}\right)$. Ventilation air for the building zone is heated using a boiler and the heating coil of the $\mathrm{AHU}\left(E_{A H U, h}\right)$, cooled with a low temperature chiller and the cooling coil of the $\mathrm{AHU}\left(E_{A H U, c}\right)$ and transported with a fan $\left(E_{A H U, f}\right)$.

In this study, since only CCA control is analysed, the $E_{C C A}$ value will be used to compare the simulation results for different controller settings. The AHU energy use is assumed not to be affected by the CCA control, which is proven by the simulation results, as shown in Sec. 4.1,

\subsection{Heating-cooling switching}

Together with these two primary performance indicators, the simultaneous occurrence of heating and cooling in 1 day provides information on the switching behaviour between heating and cooling of the concrete slab. A higher number of days per year for which heating-cooling switching occurs, indicates a bad controller performance [17]. 


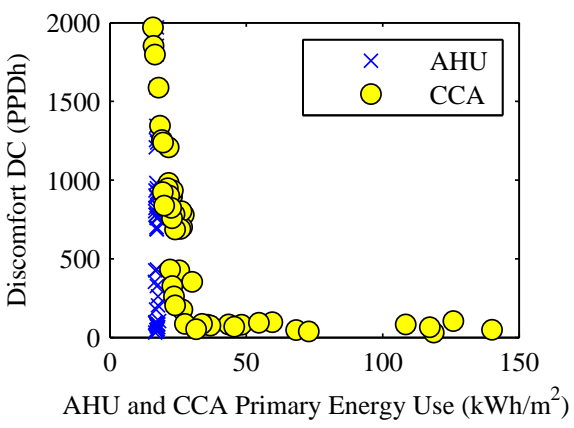

(a)

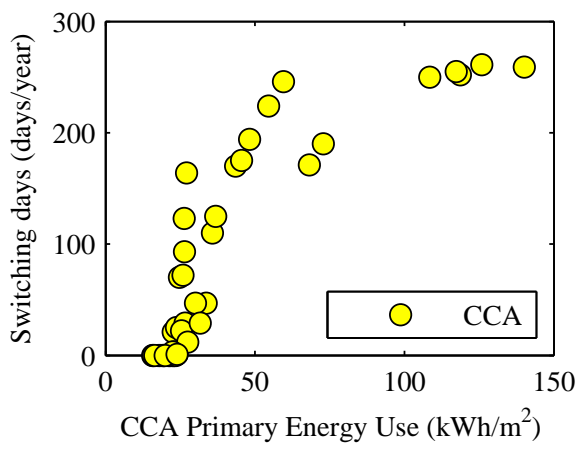

(b)

Figure 5: South CCA and AHU primary energy use against (a) thermal discomfort and against (b) the number of switching days for all the controller settings investigated (see Table 6)

\subsection{Data sign convention}

The thermal energy values are positive for heating $\left(q_{h}\right.$, heat transferred from water to CCA) and negative for cooling ( $q_{c}$, heat transferred from CCA to water). When primary energy is presented, all values are positive.

\section{Results}

\subsection{Variation of controller settings}

Fig. [5 summarizes the simulation results for all combinations of controller settings as presented in Table 6. A clear trade-off exists between energy use and thermal discomfort. A detailed analysis of the different subsets of these data reveals the underlying trends related to the different controller parameters. Generally, there is no difference in trends between the South zone, the North zone or the results for both zones together, due to the high quality solar shading. Therefore, only the results for the South zone are presented.

There are a number of controller settings that combine low energy use with low thermal discomfort. Although the zero discomfort level is never achieved, with a minimum of around $40 \mathrm{PPDh}$, some controllers come very close. The AHU primary energy use $E_{A H U}$ is varies only slightly omang the 
different controller settings as presented by the $\times$-markers in Fig. 5 , the mean of $E_{A H U}$ is $17.1 \mathrm{kWh} / \mathrm{m}^{2}$ with a standard deviation of $0.34 \mathrm{kWh} / \mathrm{m}^{2}$. Therefore, no further attention is paid to $E_{A H U}$ in the analysis of the results.

As indicated by the data for simultaneous heating and cooling in Fig. 5(b), an increase in energy use is correlated to the amount of days for which heating and cooling occur during the course of the same day (called 'switching days'). This allows to draw a first and maybe most important conclusion for a CCA controller:

Heating and cooling of CCA during 1 day is impermissible.

\subsection{The best Heating/Cooling Curve controller settings}

Zooming in into the simulation results of the Heating/Cooling Curve (HCC) controller with different settings results in Fig. 6. Controlling $T_{s}$ yields in the best controller performance. However, using $T_{i a}$ as controlled temperature also appears in the collection of controllers performing well (see also Table7). This is surprising, regarding the fact that this point has 193 switching days. Although it seems to be a good choice, taking $T_{i a}$ as controlled temperature has a big risk of overheating or -cooling the CCA, which was also addressed by Lehmann et al. [8]. The $\left(\mathrm{CONTR}=T_{i a}\right)$-setting is very sensitive to variations in the system's temperatures. For example, taking a water supply temperature setting $(\mathrm{CF}=6 /-6)$ instead of $(\mathrm{CF}=3 /-3)$ results in an increase of $E_{C C A}$ by $82 \%$, while for $T_{s}$, this is only $11 \%$. To a smaller extent, this is also true for $T_{o p}$ as the controlled temperature. The next sections will elaborate on this sensitivity.

Although the simulation results of controller settings $(\mathrm{CF}=6 /-6)$ and $(\mathrm{CF}=3 /$ $3)$ are similar, the required heat and cold production power $\left(\dot{q}_{h, \max }\right.$ and $\left.\dot{q}_{c, \max }\right)$ is much higher for $(\mathrm{CF}=6 /-6)$ compared to the more moderate setting $(\mathrm{CF}=3 /-3)$, as shown in Table 7 . This leads to a higher investment cost for the heat/cold production units. To reduce production power, it seems best not to supply too high or too low water temperatures. This consideration would make HCC2 from Table 7, with the moderate HCC-setting $(\mathrm{CF}=3 /-3)$, the best controller setting. Regarding the relation between system design and control design, the following statement can be posed: 


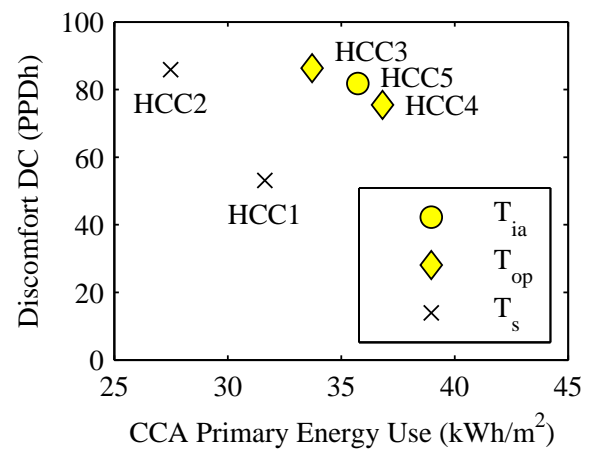

Figure 6: The controller performance for the 'best' controller settings

Table 7: The best controller settings

\begin{tabular}{cccccccc}
\hline & CONTR & CF & SET & $\begin{array}{c}E_{z} \\
\mathrm{kWh} / \mathrm{m}^{2}(\text { prim })\end{array}$ & $\begin{array}{c}D C \\
\mathrm{PPDh}\end{array}$ & $\begin{array}{c}\dot{q}_{h, \text { max }} \\
\mathrm{W} / \mathrm{m}^{2}\end{array}$ & $\begin{array}{c}\dot{q}_{c, \text { max }} \\
\mathrm{W} / \mathrm{m}^{2}\end{array}$ \\
\hline $\mathrm{HCC} 1$ & $T_{s}$ & $6 /-6$ & $0 /-2$ & 31.6 & 53 & 183 & -106 \\
$\mathrm{HCC} 2$ & $T_{s}$ & $3 /-3$ & $0 /-2$ & 27.5 & 86 & 146 & -69 \\
$\mathrm{HCC} 3$ & $T_{o p}$ & $6 /-6$ & $0 / 0$ & 33.7 & 86 & 174 & -107 \\
$\mathrm{HCC} 4$ & $T_{o p}$ & $3 /-3$ & $0 /-1$ & 36.8 & 75 & 137 & -65 \\
$\mathrm{HCC} 5$ & $T_{i a}$ & $3 /-3$ & $0 / 0$ & 35.7 & 82 & 137 & -66 \\
\hline
\end{tabular}




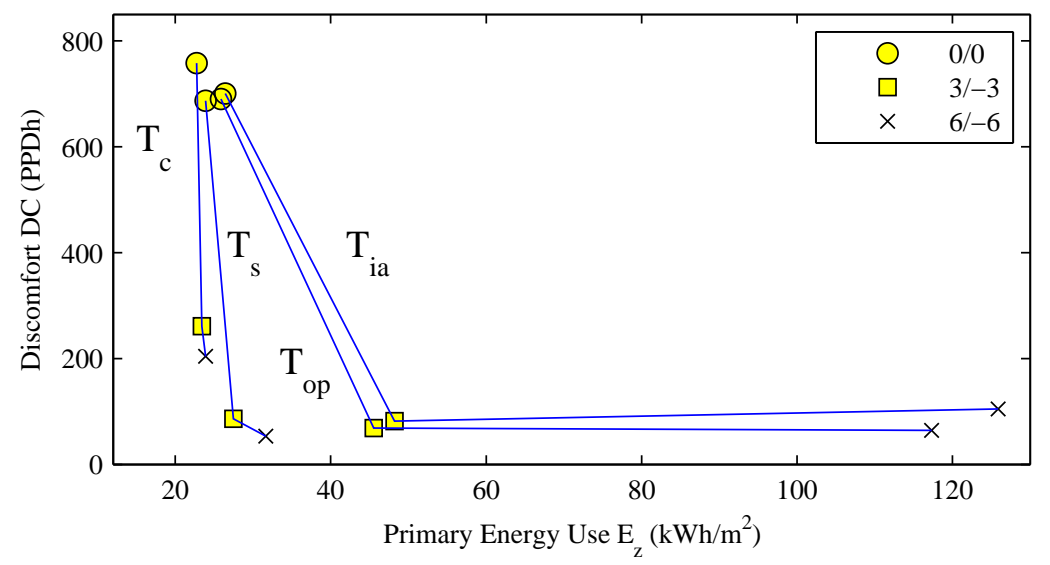

Figure 7: South zone energy use $E_{C C A}$ against thermal discomfort $D C$ for $(\mathrm{SET}=0 /-2)$ and HCC-settings $\mathrm{CF}=0 / 0,3 /-3$ and $6 /-6$

CCA system design and control design should be integrated.

\subsection{Sensitivity to $T_{\text {controlled }}$ and the heating/cooling curve cor- rection}

Fig. 7 shows the results for the heating and cooling set points $(\mathrm{SET}=0 /-2)$. The sensitivity of the controller performance to the 4 controlled temperatures $T_{i a}, T_{o p}, T_{s}$ and $T_{c}$ is presented. Also, the influence of the HCCsettings on the results is shown $(\mathrm{CF}=0 / 0,3 /-3,6 /-6)$. This figure allows to derive conclusions regarding the HCC-controller performance as a function of $T_{\text {controlled }}$ and the heating/cooling curve.

Concerning the controlled temperatures, controlling $T_{i a}$ and $T_{o p}$ is very sensitive to the heating/cooling curve settings. With the reference HCC-settings $(\mathrm{CF}=0 / 0)$, the controller performance seems insensitive to the choice of $T_{\text {controlled }}$ : all $(\mathrm{CF}=0 / 0)$ points, marked with $\circ$ in Fig. 7, are located around $700 \mathrm{PPDh}$ and $25 \mathrm{kWh} / \mathrm{m}^{2}$. Changing $\mathrm{CF}$ to $3 /-3$ and $6 /-6$ reduces thermal discomfort for all controlled temperatures. $(\mathrm{CF}=6 /-6)$ shows a rather small further decrease of $D C$ compared to $(\mathrm{CF}=3 /-3)$ for all controlled temperatures. However, the primary energy use $E_{C C A}$ is very sensitive for $T_{i a}$ and $T_{o p}$ as $T_{\text {controlled }}$, but remains almost unchanged when $T_{c}$ and $T_{s}$ are controlled. This is caused by the thermal inertia of the CCA: the response of $T_{i a}$ and $T_{o p}$ to controller signals is characterized by a significant time delay. 
This is observed by a high switching behaviour when the air temperature $T_{i a}$ is used as the controlled temperature: 163 days on average for the $T_{i a^{-}}$ points presented in Fig. 7, against no days with heating/cooling switching when the concrete core temperature $T_{c}$ is controlled. From this, it can be concluded that:

\section{Setting $T_{i a}$ or $T_{o p}$ as controlled temperature is not a robust controller setting.}

The reason why $\left(\mathrm{CONTR}=T_{c}\right)$ performs worse than $\left(\mathrm{CONTR}=T_{s}\right)$ regarding thermal comfort is due to the fact that the temperature $T_{c}$ reacts much faster to a heating or cooling action of the water supply, while the heat transfer towards the room air takes extra time. The circulation pump will therefore switch on and off too frequently, which results in a low amount of heat loaded or extracted from the CCA. Increasing the amount of heat or cold stored in the CCA-slab can be improved by a higher heating/cooling curve setting (Fig. 7): for both $\left(\mathrm{CONTR}=T_{s}\right)$ and $\left(\mathrm{CONTR}=T_{c}\right)$ the controller with $(\mathrm{CF}=3 /-3)$ and $(\mathrm{CF}=6 /-6)$ reduces thermal discomfort, while the energy use is hardly affected. The highest gain can be achieved with the change to the $(\mathrm{CF}=3 /-3)$ setting of the heating/cooling curve.

Fig. 7 shows that using the CCA surface temperature $T_{s}$ is indeed promising for achieving low thermal discomfort at a low energy cost. Using $(\mathrm{CF}=3 /-3)$ (HCC2 in Table 7) decreases $D C$ without increasing $E_{C C A}$ significantly. Increasing the HCC to (SET=6/-6) (HCC1 in Table 7) has a limited influence for $T_{s}$ as controlled temperature. Physically, $T_{s}$ is positioned 'in the middle' between $T_{o p}$, the temperature used to evaluate thermal comfort, and $T_{w s}$ the temperature at which the heat or cold is supplied. $\left(T_{s}-T_{i a}\right)$ is the driving temperature difference for the CCA-to-room heat transfer. Therefore, keeping $T_{s}$ at a setpoint temperature, means keeping the thermal power at a required level.

\subsection{Illustration of the HCC correction effect}

As an illustration of the effect of the heating and cooling curve CF-setting, the detailed results for a Thursday in a typical mid-season week of September are used. The effect of controlling $T_{o p}$ is compared with controlling $T_{s}$ 
for three different HCC-correction factors $(\mathrm{CF}=0 / 0,3 /-3,6 /-6)$.

Firstly, the results for $T_{o p}$ as the controlled temperature are presented in Figs. \&(a), (c), (e), showing $T_{o p}, T_{\text {controlled }}$ and the thermal power of the heat exchange between water and CCA $\dot{q}_{w}$. Note that for the $T_{o p}$-case the $T_{o p}$-curve and the $T_{\text {controlled }}$-curve are the same (Fig. 8(a) equals 8(c)). Nevertheless it is shown, for completeness. The vertical lines show the night setback window. The horizontal lines in Fig. 8(a) show the thermal comfort band $\left(T_{o p, \min }-T_{o p, \max }\right)$, while the horizontal lines in Fig. 8(c) are $T_{\text {set }, h}$ and $T_{\text {set, },}$, the temperature setpoints for heating and cooling. The (SET=0/-2)setting is used here. Several observations can be made from this graph:

- Cooling from the previous day results in a lower starting $T_{o p}$ for the lower cooling curves $(\mathrm{CF}=3 /-3$ and $\mathrm{CF}=6 /-6)$, since the concrete slab contains a large residual amount of cold which cools down the building after office hours. Changing the night setback schedule might solve this.

- As a consequence, heating starts up in the beginning of the day for $(\mathrm{CF}=3 /-3$ and $\mathrm{CF}=6 /-6)$, which has almost no direct effect on the room air temperature.

- Cooling starts during the day for all CF-settings investigated. However, the $(\mathrm{CF}=6 /-6)$-setting is able to cool down the CCA more quickly, and stops cooling first.

- The $(\mathrm{CF}=6 /-6)$-setting has, due to a higher cooling power, loaded too much cold in the CCA. It will cool down the room too much, requiring a heating period at the end of the day.

Secondly, looking at the same results for the CCA surface temperature $T_{s}$ as the controlled temperature, Figs. E(b) (d) (f) show that for this setting the response of the controlled temperature $T_{s}$ to a controller action is much faster. When the heating/cooling curve is set to $(\mathrm{CF}=+3 /-3)$ or $(\mathrm{CF}=6 /$ 6 ), the system is able to keep $T_{s}$ close to the required temperature $T_{s e t, c}$, as shown in Fig. 8(d), For the $(\mathrm{CF}=6 /-6)$-setting, Fig. 8(f) shows that this automatically results in an intermittent pump operation. When controlling $T_{s}$ combined with the heating/cooling curve settings $(\mathrm{CF}=3 /-3$ and $\mathrm{CF}=6 /-$ $6)$ and the setpoint setting $(\mathrm{SET}=0 /-2)$, the $\mathrm{CCA}$ will react fast enough to 


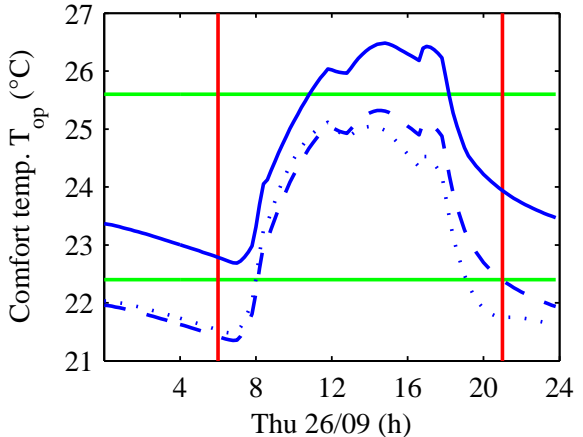

(a)

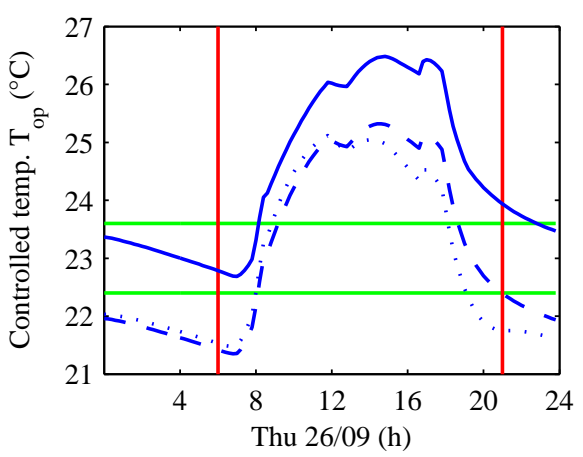

(c)

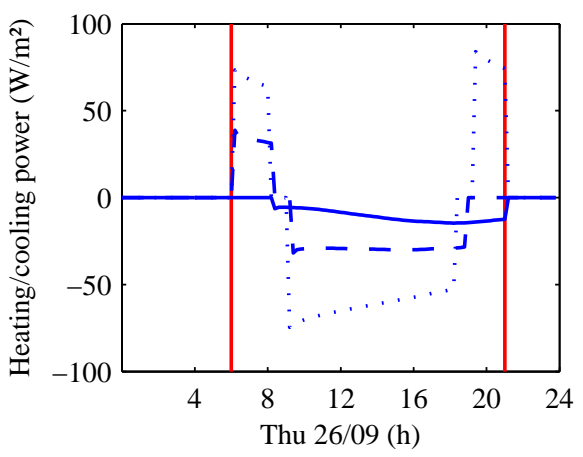

(e)

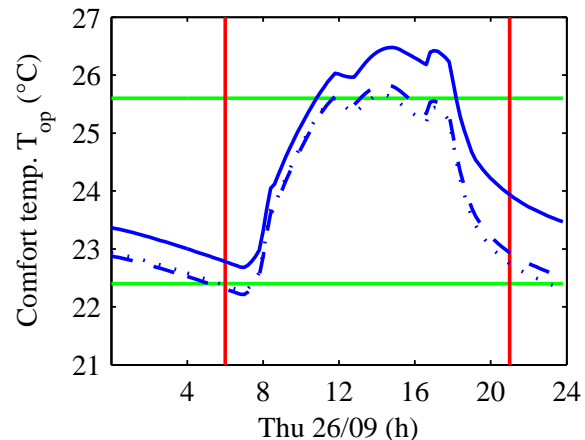

(b)

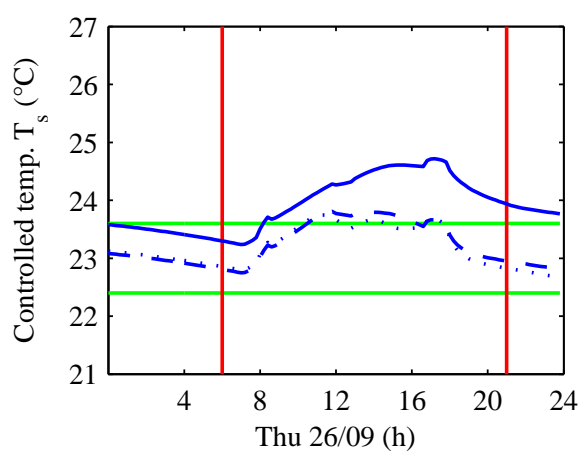

(d)

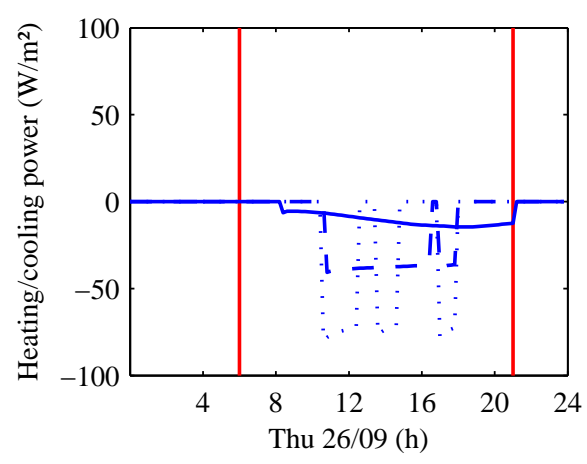

(f)

Figure 8: South zone $T_{o p}, T_{\text {controlled }}$ and the thermal water power $\dot{q}_{w}$ for Thursday of the mid-season week.

(a) (c) (e) $T_{o p}$ as controlled temperature, (b) (d) (f) $T_{s}$ as controlled temperature,

Controller settings: $\mathrm{SET}=0 /-2 ; \mathrm{CF}=0 / 0$ : solid line; $\mathrm{CF}=3 /-3$ : dashed line; $\mathrm{CF}=6 /-6$ : dotted line,

Vertical lines indicate the night setback window, (a) (b) Horizontal lines: $T_{o p, \min }-T_{o p, \max }$ range, (c) (d) Horizontal lines: $T_{\text {set }, h}-T_{\text {set }, c}$ range 
compensate heat losses or loads in the office zone, resulting in a lower yearly thermal discomfort, as was shown in Fig. 7 .

Fig. 8(f) also shows that the switching behaviour is no longer existing (only cooling during the day). This controller avoids to cool down the CCA too much, which results in a higher temperature at the beginning of the next day, eliminating the need for heating.

\subsection{HCC2 controller behaviour}

Fig. 9 shows the operative temperature (solid line) and the CCA core temperature (dashed line) of the South zone for the controller setting HCC2, together with the corresponding heating and cooling power for a typical winter and summer week. The controller tries to keep $T_{c}$ at level, but due to the night and weekend setback settings, the system requires a high start-up power. In the winter situation a large heating power is needed to deliver the required supply water temperatures. These high power peaks occur at 6AM, the start of the HVAC-operation. Due to the internal gains, the operation time in winter will be shorter than in a summer situation. A limited production power would lead to longer operation times. In the summer situation, it appears that undercooling exists, leading to a heating need at the start of Tuesday and Friday.

\subsection{HCC2 controller with limited production power}

The required heating and cooling power that has to be delivered by the water circuit, is high: certainly for heating, where the yearly maximum heating power $\dot{q}_{h, \max }$ equals $146 \mathrm{~W} / \mathrm{m}^{2}$, but also for cooling, where $\dot{q}_{c, \max }$ is $69 \mathrm{~W} / \mathrm{m}^{2}$. The heating and cooling load calculations resulted in respectively $26 \mathrm{~W} / \mathrm{m}^{2}$ and $25 \mathrm{~W} / \mathrm{m}^{2}$.

In order to investigate the impact of a limited heating and cooling production power on the performance of the controller, the HCC2 controller is applied to a heat/cold production system with two different capacities:

1. $\dot{q}_{h, 2 \times \text { des }}=52 \mathrm{~W} / \mathrm{m}^{2}$ and $\dot{q}_{c, 2 \times \text { des }}=50 \mathrm{~W} / \mathrm{m}^{2}$ : a heating and cooling power limited to twice the design value. 


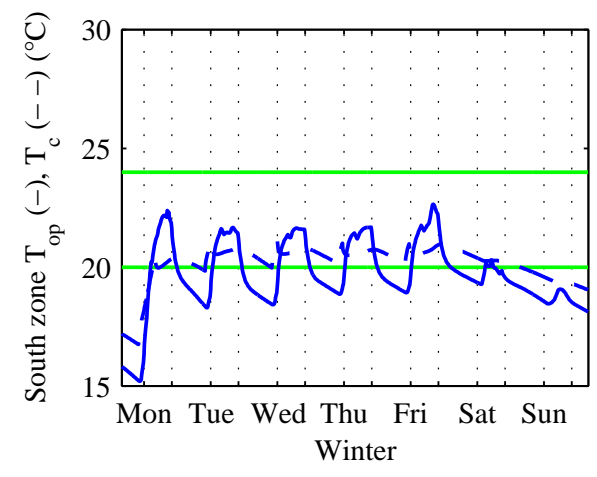

(a)

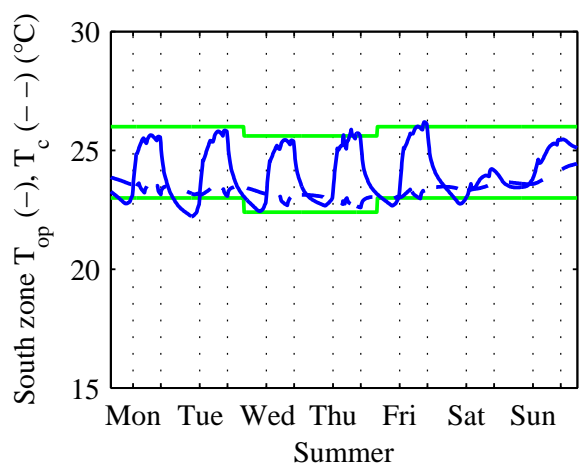

(c)

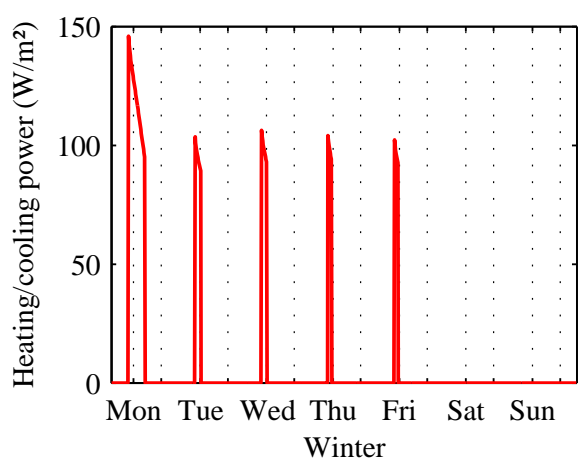

(b)

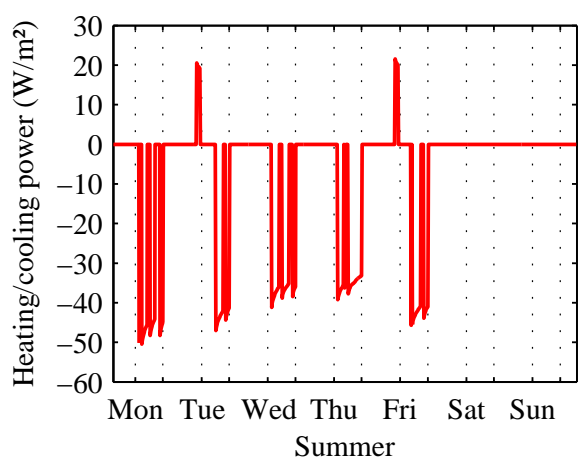

(d)

Figure 9: South zone results with the HCC2 controller: Operative and CCA core temperatures and heating or cooling power (water circuit) (a) (b) for a typical winter week and (c) (d) for a typical summer week. The thermal comfort range is indicated, as well as the $8 \mathrm{AM}-6 \mathrm{PM}$ office hours. Note the different scales of the $\mathrm{Y}$-axis for heating/cooling power. 
2. $\dot{q}_{h, \text { des }}=26 \mathrm{~W} / \mathrm{m}^{2}$ and $\dot{q}_{c, \text { des }}=25 \mathrm{~W} / \mathrm{m}^{2}$ : a heating and cooling power limited to the design value.

Fig. 10 presents the South zone load duration curve for the three CCA cases: unlimited power (Fig. 10(a)), limited to twice the design value (Fig. 10(b) and limited to the design value (Fig. 10(c)].

As explained previously, the maximum heating power in the case of unlimited production power (Fig. 10(a) is almost 6 times higher than the design heat load of $\dot{q}_{h, \text { des }}=26 \mathrm{~W} / \mathrm{m}^{2}$. For cooling the maximum cooling power is almost 3 times the design value of $\dot{q}_{c, \text { des }}=25 \mathrm{~W} / \mathrm{m}^{2}$. These high production powers would induce too high investment costs.

The reason for this difference in maximum heating $\left(6 \times \dot{q}_{h, d e s}\right)$ and maximum cooling power $\left(3 \times \dot{q}_{c, d e s}\right)$ can be explained by looking at the CCA behaviour, as e.g. in Fig. 9, Heating starts up at the beginning of the day, when the building, and therefore also the concrete slab, is cold. On the other hand, cooling starts up when the zone temperature is increasing during the day. The difference between $T_{c}$ and $T_{w s}$ will therefore be larger for the heating situation compared to the cooling situation. Fig. 10(d) shows this temperature difference throughout the year when the heating or cooling starts up. The mean temperature difference at start-up for the whole year, $\overline{T_{c}-T_{w s}}$, is $-5.9^{\circ} \mathrm{C}$ for heating but only $2.5^{\circ} \mathrm{C}$ for cooling.

The results show clearly that in order to control CCA appropriately, the available production power should be taken into account. The mutual interaction between design and control is very important in CCA buildings.

For the HCC2 controller, the cooling power of the $\dot{q}_{2 \times d e s}$-case is sufficient. This is derived from the load duration curve for cooling: Fig. 10(a) and Fig. 10(b) are almost identical. For heating, however, this is not the case. The load duration curve for heating (Fig. 10(b) is extended in time to compensate for the lower heating power. If a load duration curve has a horizontal part equal to the installed power, when it is ON, this means that for those hours the production system is working at its maximum power. Heating is almost always working at its maximum power, indicating that in the heating case the production system is never able to deliver the water temperatures 


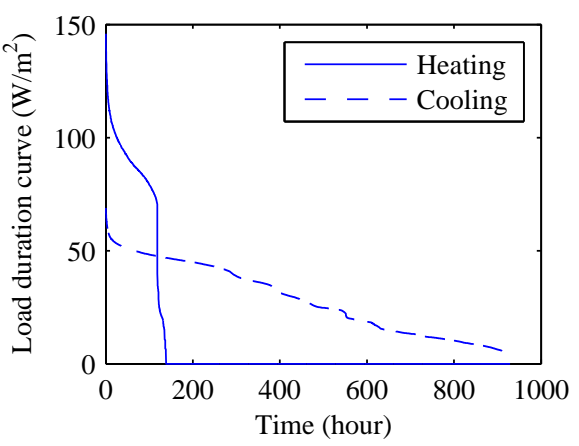

(a)

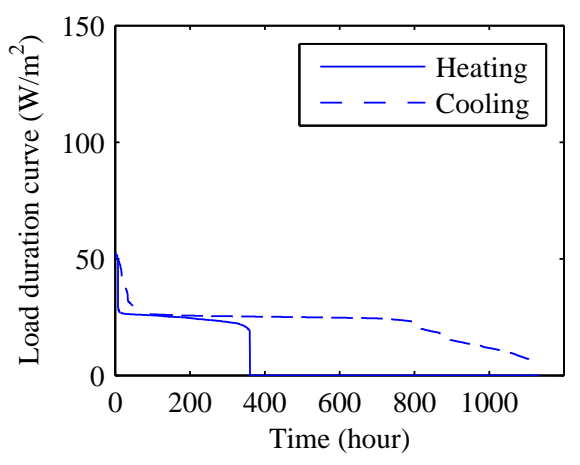

(c)

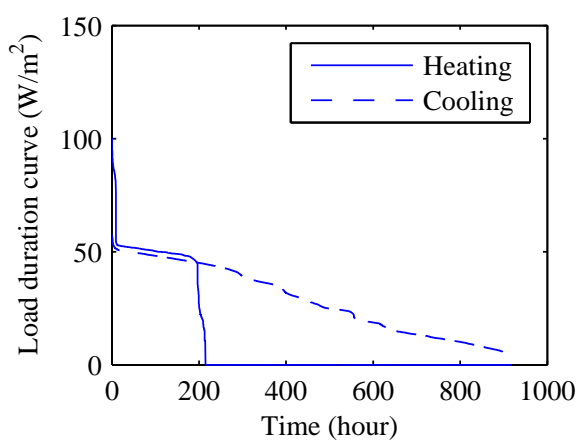

(b)

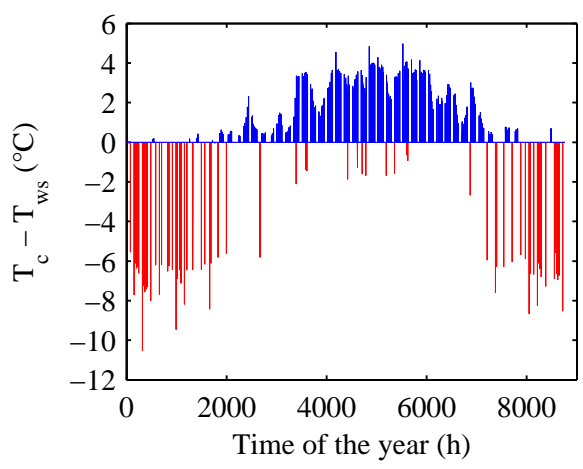

(d)

Figure 10: Heating and cooling load duration curve for (a) the HCC2 controller with unlimited power $\dot{q}$, (b) with $2 \times \dot{q}_{d e s}$ and (c) with $\dot{q}_{d e s},(\mathrm{~d})$ the temperature difference $T_{c}-T_{w s}$ at start up moments of heating (negative values) and cooling (positive values) in the $\dot{q}_{\text {unlimited }}$-case 


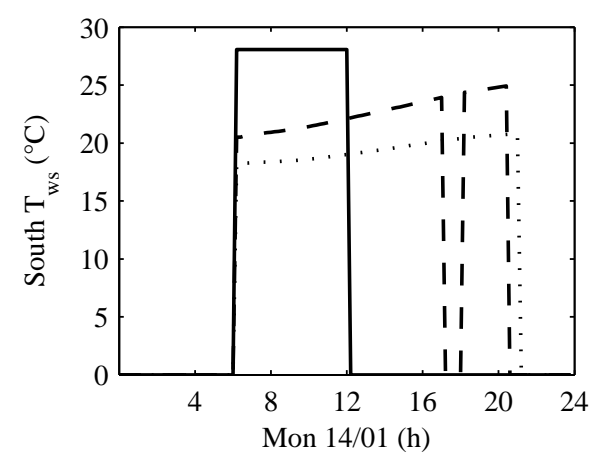

(a)

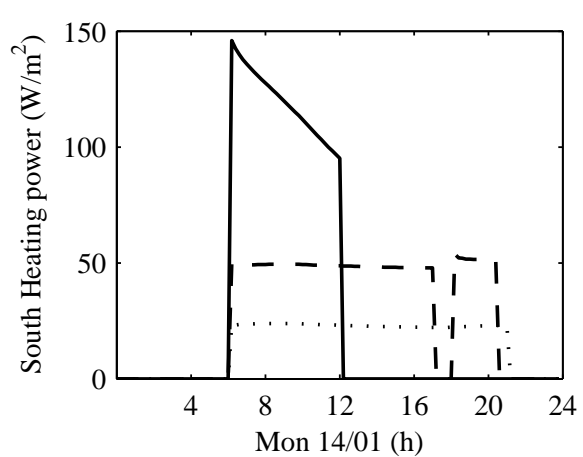

(b)

Figure 11: Difference between $\dot{q}_{h, \text { des }}(:), \dot{q}_{h, 2 \times \text { des }}(--)$ and $\dot{q}_{h, \text { unlim }}(-)$ for a typical winter day (a) water supply temperature (the water supply set point $T_{w s, h s v}=28^{\circ} \mathrm{C}$ ) and (b) heating power)

requested by the controller.

For the $\dot{q}_{d e s^{-}}$-case, in Fig. 10(c), both heating and cooling power are at maximum for the main part of the operating hours. In this case, both in heating and cooling, the production system is not able to deliver the water temperatures requested by the controller for the majority of the operating hours.

Fig. 11 shows detailed results for a typical winter Monday. For the $\dot{q}_{h, 2 \times d e s^{-}}$ and $\dot{q}_{h, d e s^{-c a s e}}$ the water supply set point $T_{w s-h s v}=28^{\circ} \mathrm{C}$ is never reached. This results in a longer operation time at a lower heating power. The controller performance decreases in this case (with respect to thermal comfort), since less heating is provided compared to the $\dot{q}_{h, \text { unlim-case. }}$ The night setback switch time should be brought forward in this typical winter-Monday situation. However, the impact on the yearly thermal discomfort for the $\dot{q}_{h, 2 \times d e s^{-c a s e}}$ is limited $(D C=114 \mathrm{PPDh}$ as shown in Table 8), while the energy use even decreases slightly. On the other hand, limiting to the design power $\left(\dot{q}_{\left.h, d e s^{-c a s e}\right)}\right.$ causes the thermal discomfort to increase substantially $(D C=230 \mathrm{PPDh})$, while the impact on the energy use is limited.

\subsection{Alternating zone operation}

An interesting observation from Table 8 is that for the case with the production power limited to $\dot{q}_{2 \times d e s}$, the maximum supplied heating power $\dot{q}_{h, \text { max }}$ is 
Table 8: Yearly energy use and maximum heating and cooling power of the South zone for the $\mathrm{HCC} 2$ controller with unlimited and limited production power

\begin{tabular}{lcccc}
\hline & $\begin{array}{c}E_{z} \\
\mathrm{kWh} / \mathrm{m}^{2}\end{array}$ & $\begin{array}{c}D C \\
\mathrm{PPDh}\end{array}$ & $\begin{array}{c}\dot{q}_{h, \text { max }} \\
\mathrm{W} / \mathrm{m}^{2}\end{array}$ & $\begin{array}{c}\dot{q}_{c, \text { max }} \\
\mathrm{W} / \mathrm{m}^{2}\end{array}$ \\
\hline$\dot{q}_{\text {unlim }}$ & 27.5 & 86 & 146 & -69 \\
$\dot{q}_{2 \times \text { des }}$ & 27.0 & 114 & 100 & -58 \\
$\dot{q}_{\text {des }}$ & 25.9 & 230 & 52 & -50 \\
\hline
\end{tabular}

almost double the installed heating production power of $52 \mathrm{~W} / \mathrm{m}^{2}$. Also for the $\dot{q}_{h, d e s}$-case, the maximum supplied heating and cooling power are double the installed production power. This is caused by a system-behaviour here referred to as the alternating zone operation.

When discussing the controller performance for all setting combinations in Sec. 4.2, the HCC1 option (SET=6/-6) was abandoned because of the high heating and cooling power required. Simulating the HCC1-controller with a limited power of $\dot{q}_{h, 2 \times d e s}$, however, reveals the alternating zone operation. Since the (SET=6/-6) controller setting is combined with $T_{s}$ as the controlled temperature for HCC1, the setpoint is reached relatively fast. For the HCC1 controller with $\dot{q}_{2 \times \text { des }}$, the primary energy use $E_{C C A}$ is $29.7 \mathrm{kWh} / \mathrm{m}^{2}$ and the thermal discomfort $D C$ amounts to $102 \mathrm{PPDh}$, which means that the energy use is slightly higher than for the HCC2 controller (row 2 in Table 8) and the thermal discomfort slightly lower.

Using the HCC1-controller results in a South and North zone pump operation which do rarely coincide. Fig. 12(a) shows for a typical day requiring cooling, that the cooling load is alternated between South and North zone. Only around 2 PM both zones require cooling simultaneously. This means that, although the cooling production power is designed at $50 \mathrm{~W} / \mathrm{m}^{2}$, in time periods during which cooling is operating for only one of the zones, this zone has the full production power at its disposal, meaning $100 \mathrm{~W} / \mathrm{m}^{2}$ for that specific zone.

The duration load curve of this HCC1 controller (Fig. 12(b) shows that in 


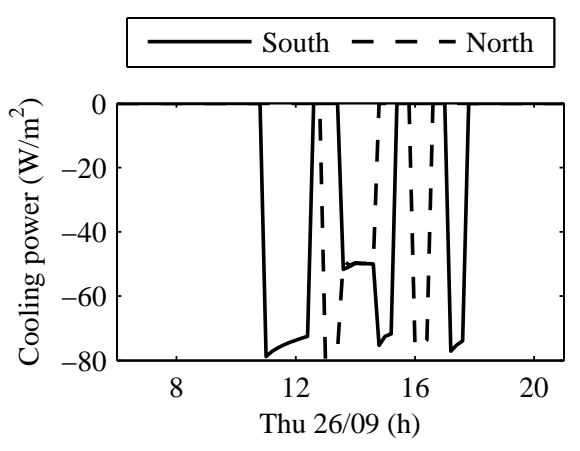

(a)

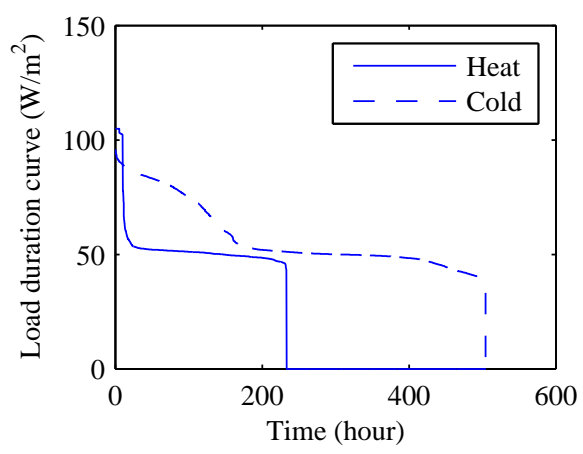

(b)

Figure 12: HCC1 controller performance with $\dot{q}_{2 \times d e s}$ : (a) alternating NorthSouth zone operation and (b) the duration load curve of the South zone

the case of cooling almost for $200 \mathrm{~h}$ the South cooling power is larger than $50 \mathrm{~W} / \mathrm{m}^{2}$, which refers to alternating zone operation. For this period, not even the full available power of $100 \mathrm{~W} / \mathrm{m}^{2}$ is required, this means that the requested set point will always be met. The heating load duration curve shows that almost never alternating zone behaviour occurs, because heating is typically required at $6 \mathrm{AM}$, when the night setback switches. This is the same time for both South and North zone.

The flat parts in the load duration curves are time periods during which both zones are operating and the production system is working at full power. Temperature set points are not met during these periods. For heating this appears to be almost always the case. Again, as was already derived from Fig. 11, it is concluded that the available heating power is not sufficient.

\subsection{Night set back settings}

The HCC2 (and HCC1) controller still has problems due to the night set back settings. Certainly in the case of heating, switching to comfort limits at $6 \mathrm{AM}$ gives rise to comfort violations and high power peaks due to the large thermal capacity of the CCA. Also, the simultaneous operation of both South and North zone prevents alternating zone operation in heating mode. The impact of these night setback settings is investigated by comparing:

1. 9 PM - 6 AM night set back: original settings 


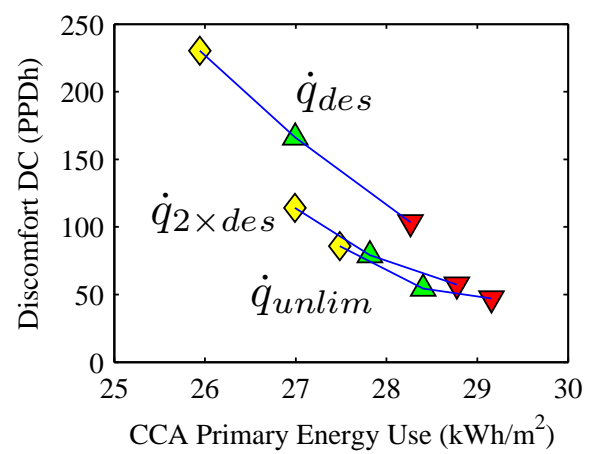

Figure 13: Impact of night setback settings on the controller performance for the South zone and the HCC2 controller, for a production system sized to $\dot{q}_{d e s}, \dot{q}_{2 \times d e s}$ and $\dot{q}_{\text {unlim }}$, for a controller with night setback $(\diamond)$, reduced night setback $(\triangle)$ and no night setback $(\boldsymbol{\nabla})$.

2. $9 \mathrm{PM}-3 \mathrm{AM}$ night set back: advancing the morning switch

3. No night setback

The primary energy use and thermal discomfort results are shown in Fig. 13 for the HCC2 controller and for three cases: 1) unlimited production power, 2) production power limited to $\dot{q}_{2 \times d e s}$, twice the design value, and 3) to $\dot{q}_{d e s}$, the design value for the production power. These results show that omitting night setback clearly improves thermal comfort, but against a small increase in energy use.

Table 9 shows that the improved thermal comfort is mainly caused by a reduction of the number of hours during which the operative temperature is too low, which is as expected since the night setback was mainly causing problems in the heating regime. The impact on overheating is limited. Consequently, this leads to a $20 \%-30 \%$ increase in heating energy, while the impact on the cooling energy is limited to $3 \%$ for $\dot{q}_{2 \times d e s}$ and $-4 \%$ for $\dot{q}_{d e s}$.

Fig. 14 (a) (b) show that for a winter situation, with the production system sized to $\dot{q}_{d e s}$, the impact of the night setback setting is large. When no night setback is applied, $T_{o p}$ is kept much higher and discomfort is reduced. Moreover, the system automatically operates in alternating zone mode, which is very important for the sizing of the production system. Fig. 14 presents 


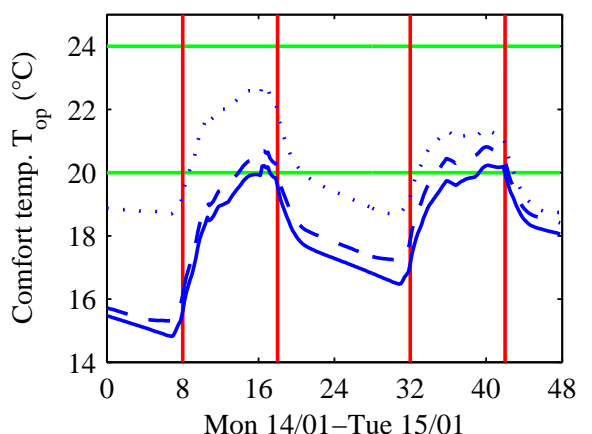

(a)

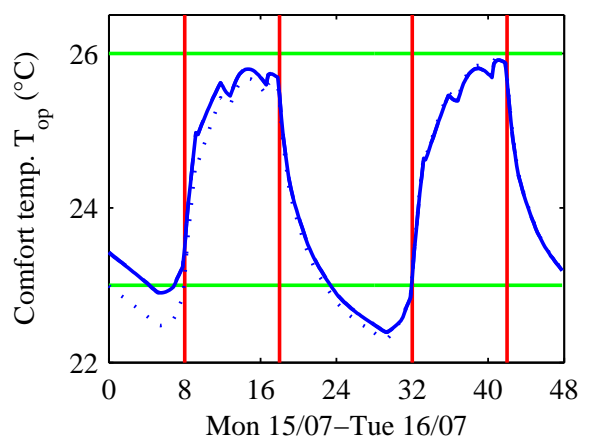

(c)

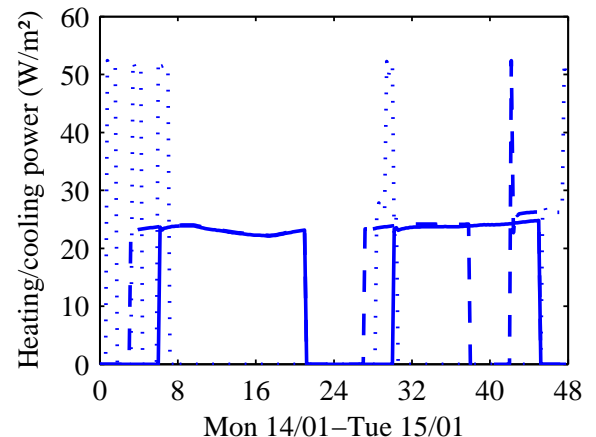

(b)

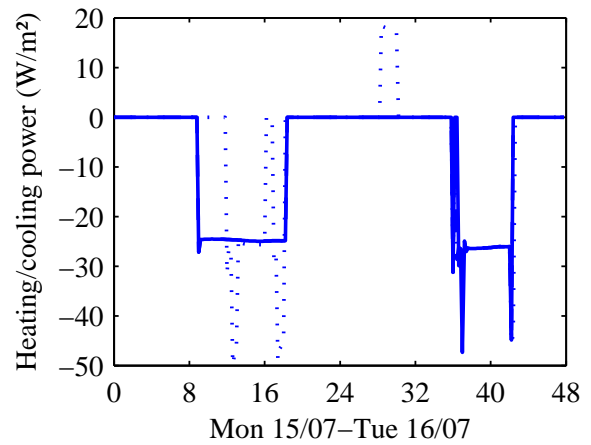

(d)

Figure 14: Effect of the night setback settings for the $\dot{q}_{d e s}$-case and for (a) two consecutive winter days and (c) (d) two consecutive summer days, with (a) (c) the operative temperature and (b) (d) the corresponding heating/cooling power.

The horizontal lines indicate the comfort band and the vertical line indicate the office hours. NS 9 PM-6 AM: full line (-), NS 9 PM3 AM: dashed line (- -), No NS: dotted line (...). 
Table 9: Effect of the night setback settings on the yearly number of hours below and above the PMV-limit and the yearly thermal heating and cooling energy.

\begin{tabular}{llcccc}
\hline $\begin{array}{l}\text { Production } \\
\text { power }\end{array}$ & $\begin{array}{l}\text { Night setback } \\
\text { settings (NS) }\end{array}$ & $\begin{array}{c}\text { Number of hours } \\
\text { PMV<-0.5 } \\
\text { PMV }>0.5\end{array}$ & $\begin{array}{c}\text { Heating } \\
\text { energy } \\
\text { (Too cold) }\end{array}$ & $\begin{array}{c}\text { Cooling } \\
\text { energy } \\
\text { (Too warm) }\end{array}$ & $\begin{array}{l}\mathrm{kWh} / \mathrm{m}^{2}{ }_{t h} \\
\mathrm{kWh} / \mathrm{m}^{2}{ }_{t h}\end{array}$ \\
\hline \multirow{2}{*}{$\dot{q}_{2 \times \text { des }}$} & NS 9 PM-6 AM & 240 & 191 & 10.6 & 26.2 \\
& NS 9 PM-3 AM & 146 & 174 & 11.3 & 26.6 \\
& No NS & 77 & 172 & 12.5 & 26.9 \\
\hline \multirow{2}{*}{$\dot{q}_{\text {des }}$} & NS 9 PM-6 AM & 396 & 432 & 9.0 & 25.2 \\
& NS 9 PM-3 AM & 248 & 380 & 10.1 & 25.6 \\
& No NS & 90 & 343 & 11.9 & 26.1 \\
\hline
\end{tabular}

the results with production sized to only $\dot{q}_{d e s}$, so a value of around $50 \mathrm{~W} / \mathrm{m}^{2}$ means that only 1 zone is operating. So, compared to Sec. 4.7, alternating zone operation is now achieved with $\dot{q}_{d e s}$ instead of $\dot{q}_{2 \times d e s}$ and with a heating/cooling curve correction of $(\mathrm{CF}=3 /-3)$ instead of $(\mathrm{CF}=6 /-6)$, only by allowing the system to operate the whole night.

For cooling, in Figs. 14(c) $(\mathrm{d})$, the impact of omitting night setback is very limited. $T_{o p}$ is reduced slightly and alternating zone operation is available, but not always. For Tuesday 16/07 in Fig. 14(d), the $\dot{q}$-pattern is identical for all three night setback-settings. Moreover, in the NO night setback case, heating starts up shortly around $28 \mathrm{~h}$ because the system is constantly working within the narrow temperature band.

This difference between heating and cooling is evidently caused by the fact that the highest heat loss occurs during the night, while the highest heat gains occur during the office hours. So, applying night setback or not, affects mainly heating and not so much cooling.

This impact reflects also in the load duration curve. Fig. 15] shows the load duration curve of the 9 PM-6 AM night setback and of the NO-night setback setting, both for heating and cooling. The cooling load duration curve is hardly affected by the night setback setting. For heating, however, the impact is significant. With night setback, shown by the full line in Fig. 15(a), 


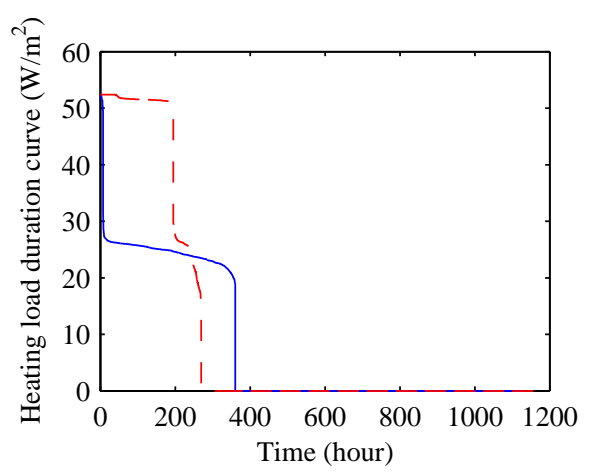

(a)

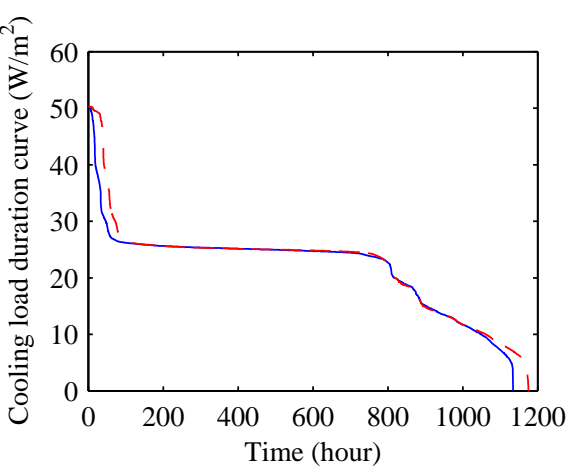

(b)

Figure 15: Load duration curve of (a) heating and of (b)] cooling for the HCC2 controller with 9 PM-6 AM night setback (-) and without night setback $(--)$

the system operates constantly at its maximum power of $\dot{q}=26 \mathrm{~W} / \mathrm{m}^{2}$, which means that both zones operate simultaneously. Without night setback, however, shown by the dashed line in Fig. 15(a), the system also operates at maximum power, but with only 1 single zone operating for the main part of the time (where $\dot{q}=52 \mathrm{~W} / \mathrm{m}^{2}$ ).

The fact that the system, both in heating and cooling, is constantly working at its thermal power limits, means that this $\mathrm{HCC} 2$ controller, without night setback, is working at its maximum performance: energy use and thermal discomfort are minimal, while the installed production power is low and equals steady-state conditions. Improving the controller performance even further at a fixed production unit capacity, will require a completely different control strategy.

\subsection{Behaviour of the HCC2 controller with design produc- tion power and without night setback}

Finally, Fig. 16 shows the behaviour of the CCA-system with an installed production power $\dot{q}_{d e s}$ equal to the steady-state design value and with the 'best' conventional feedback controller settings (HCC2). Apparently, this behaviour comes down to keeping the CCA-core temperature $T_{c}$ at a level which is slightly higher $\left( \pm 1^{\circ} \mathrm{C}\right)$ than the lower thermal comfort limit during the whole year. Given its simplicity as a CCA controller guideline, this 
is a very important conclusion. Without including prior knowledge when setting up the simulation experiment, this conclusion confirms the constant temperature control as proposed by Olesen [10].

In winter, this ensures sufficient thermal power to avoid a too large temperature drop during the night and weekend. During the day, the limited temperature level can provide some cooling to compensate for the occuring heat gains.

In summer, this setting provides cooling power to the zone to compensate for the heat gains, but avoids undercooling outside the office hours. This controller makes maximal use of the allowed thermal comfort band.

Since the installed production power is lower than the peak power determined by the cooling load calculation (the average load instead of the peak load is used to determine the design value, see Sec. 2.3), this also proves that CCA combined with this appropriate control strategy operates as a peak-shaving system.

\section{Conclusions}

The controller settings have a large impact on the required heat and cold production power, thereby proving the important mutual interaction between the design of a CCA building and the chosen control strategy.

Inappropriate control settings result in switching between heating and cooling during the same day, which on its turn results in an energy use increase. This switching behaviour has to be avoided in CCA control by taking the concrete surface or core temperature as the controlled temperature and by avoiding a too high heating curve and a too low cooling curve.

The best controller performance is achieved with a heating curve/cooling curve which is slightly higher/lower $\left(3^{\circ} \mathrm{C}\right)$ than determined by the steadystate design, together with the CCA ceiling surface temperature as the controlled temperature, by starting up cooling when $T_{\text {ceiling,surface }}$ is $2^{\circ} \mathrm{C}$ lower than the maximum comfort temperature and without using night setback. 


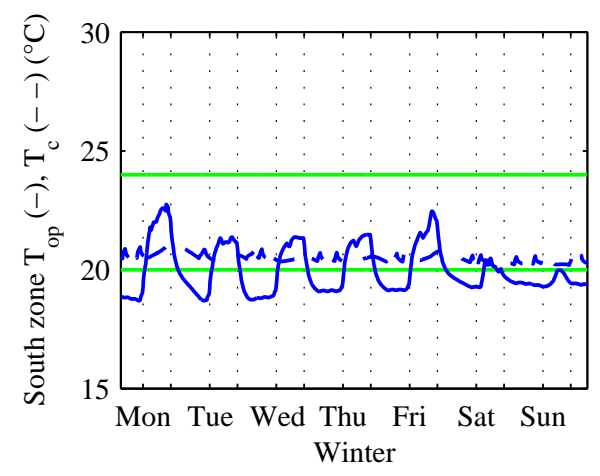

(a)

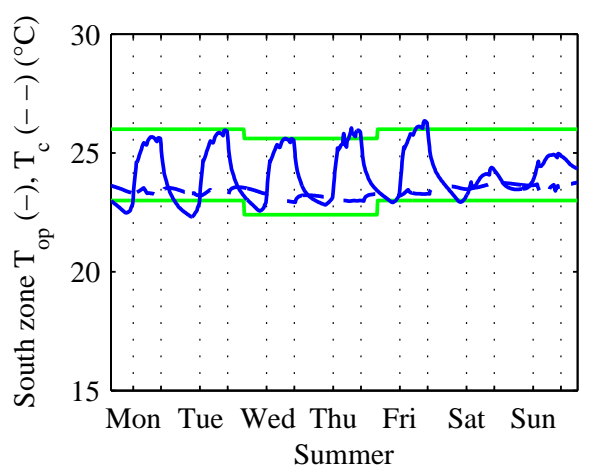

(b)

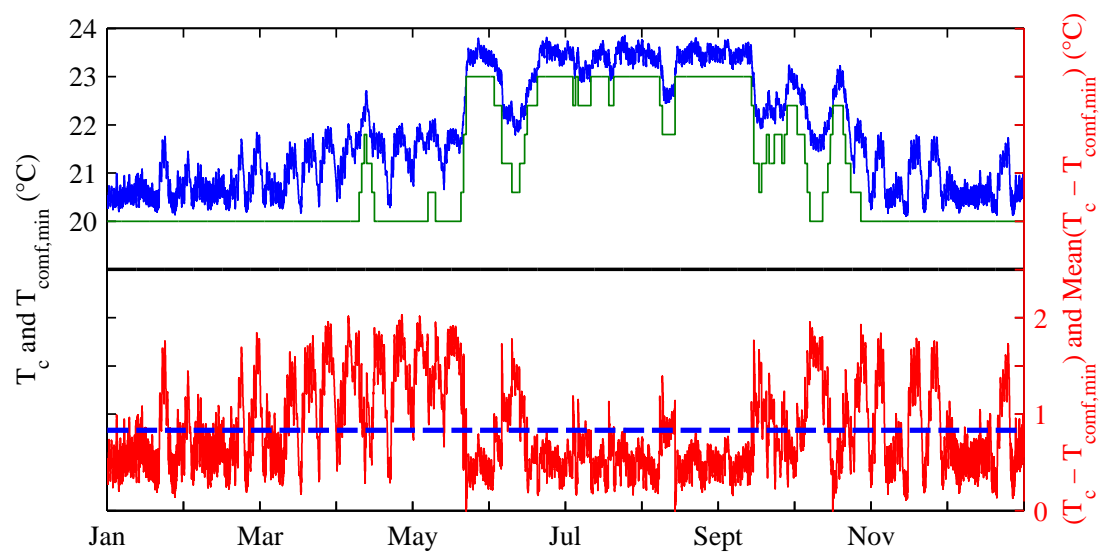

(c)

Figure 16: South zone results with the $\mathrm{HCC} 2$ controller without night setback: Operative and CCA core temperatures (a) for a typical winter week and (b) for a typical summer week. The thermal comfort range is indicated, as well as the $8 \mathrm{AM}-6 \mathrm{PM}$ office hours. (c) shows $T_{c}$ and $T_{\text {comf }, \text { min }}$ in the upper part and $\left(T_{c}-T_{\text {comf }, \text { min }}\right)$ and it's mean in the lower part. 
Night setback is absolutely required when heating with CCA, but not necessarily when cooling.

Using high/low water temperatures to supply the CCA, results in a faster response of the CCA-slab, but with more heat stored or extracted from the slab, and therefore risking overheating or undercooling of the office zone.

A lower installed production power is required when the controller keeps the CCA core temperature closer to the heating/cooling water temperature. A colder concrete slab results in a smaller temperature difference between the concrete core temperature $T_{c}$ and the water supply temperature $T_{w s}$, and therefore, a smaller production power. A similar reasoning applies to the heating regime.

Alternating zone operation, during which each zone operates alternately, should be applied to ensure that the full production power can be directed to 1 single zone. In this way, the large transient thermal power of CCA can be delivered by a production system which is designed with steady-state calculations. CCA can act as a peak shaving system, but only with an appropriate controller, which enables alternating zone control.

The behaviour of the conventional feedback controller with the best energy and thermal comfort performance comes down to keeping the concrete temperature at a constant level of around $1^{\circ} \mathrm{C}$ above the lower thermal comfort limit during the whole year. This ensures that the CCA provides enough thermal power, but not too much deviating from the required comfort temperature, otherwise the self-regulating effect of CCA is lost and subcooling or overheating might occur. Combined with a limited installed production power, designed by a simple steady-state analysis of building and CCA and lower than the required peak power, this control strategy yields an acceptable performance.

\section{References}

[1] Bureau voor Normalisatie (nbn). NBN B 62-002: Thermal performance 
of buildings - Calculations of thermal transmittances of building components and building elements - Calculation of transmission and ventilation heat transfer coefficients, 2008.

[2] Europan Committee for Standardisation. EN12831: Heating systems in buildings - Method for calculation of the heat design load, 2003.

[3] European Committee for Standardisation. EN15251: Indoor environmental input parameters for design and assessment of energy performance of buildings adressing indoor air quality, thermal environment, lighting and accoustics, 2007.

[4] European Committee for Standardisation. EN 15377-3 Heating systems in buildings - Design of embedded water based surface heating and cooling systems - Part 3: Optimizing for use of renewable energy sources, 2007.

[5] W. Güntensperger, M. Gwerder, A. Haas, B. Lehman, F. Renggli, and J. Tödtli. Control of concrete core conditioning systems. In 8th REHVA World Congress for Building Technologies (Clima 2005), page 8pp., Lausanne, Switzerland.

[6] International Organization for Standardization. EN ISO 7730(2005) : Ergonomics of the thermal environment - Analytical determination and interpretation of thermal comfort using calculation of the PMV and PPD indices and local thermal comfort criteria., 2005.

[7] J. Kolarik, J. Toftum, B. W. Olesen, and K. L. Jensen. Simulation of Energy Use, Human Thermal Comfort and Office Work Performance in Buildings with Moderately Drifting Operative Temperatures. Energy and Buildings, 43:2988-2997, 2011.

[8] B. Lehmann, V. Dorer, and M. Koschenz. Application range of thermally activated building systems tabs. Energy and Buildings, 39(5): 593-598, May 2007.

[9] C. Neumann and S. Herkel. Langzeitmonitoring der Demonstrationsgebäude im Rahmen des Forschungs- programms EnBau:MONITOR. Technical report, Frauenhofer ISE, Gruppe Solares Bauen, Freiburg, 2005 . 
[10] B. W. Olesen. Cooling and heating of buildings by activating their thermal mass with embedded hydronic pipe systems. In $A S H R A E$ CIBSE conference, page 19, Dublin, Ireland, 2001.

[11] B. W. Olesen, K. Sommer, and B. Düchting. Control of Slab Heating and Cooling Systems Studied by Dynamic Computer Simulations. ASHRAE Transactions, 108(2):698-707, 2002.

[12] D. Rijksen, C. Wisse, and A. van Schijndel. Reducing peak requirements for cooling by using thermally activated building systems. Energy and Buildings, 42(3):298-304, Mar. 2010. ISSN 03787788.

[13] S. Schiavon, K. H. Lee, F. Bauman, and T. Webster. Influence of raised floor on zone design cooling load in commercial buildings. Energy and Buildings, 42(8):1182-1191, Aug. 2010.

[14] S. Schiavon, K. H. Lee, F. Bauman, and T. Webster. Simplified calculation method for design cooling loads in underfloor air distribution (UFAD) systems. Energy and Buildings, 43(2-3):517-528, Feb. 2011.

[15] Solar Energy Laboratory. Trnsys 17: A transient system simulation program. University of Madison, Wisconsin, 2009.

[16] M. Sourbron. Dynamic thermal behaviour of buildings with Concrete Core Activation. PhD thesis, KU Leuven, Leuven, 2012.

[17] M. Sourbron, R. De Herdt, T. Van Reet, W. Van Passel, M. Baelmans, and L. Helsen. Efficiently produced heat and cold is squandered by inappropriate control strategies: A case study. Energy and Buildings, 41(10):1091-1098, Oct. 2009.

[18] Z. Tian and J. A. Love. Energy performance optimization of radiant slab cooling using building simulation and field measurements. Energy and Buildings, 41(3):320-330, Mar. 2009.

[19] Vereind Deutscher Ingenieure. VDI2078: Berechnung der Kühllast klimatisierter Räume (VDI-Kühllastregeln), 1996.

[20] M. Zaheer-uddin, Z. L. Zhang, and S. H. Cho. Augmented control strategies for radiant floor heating systems. International Journal of Energy Research, 26(1):79-92, Jan. 2002. 